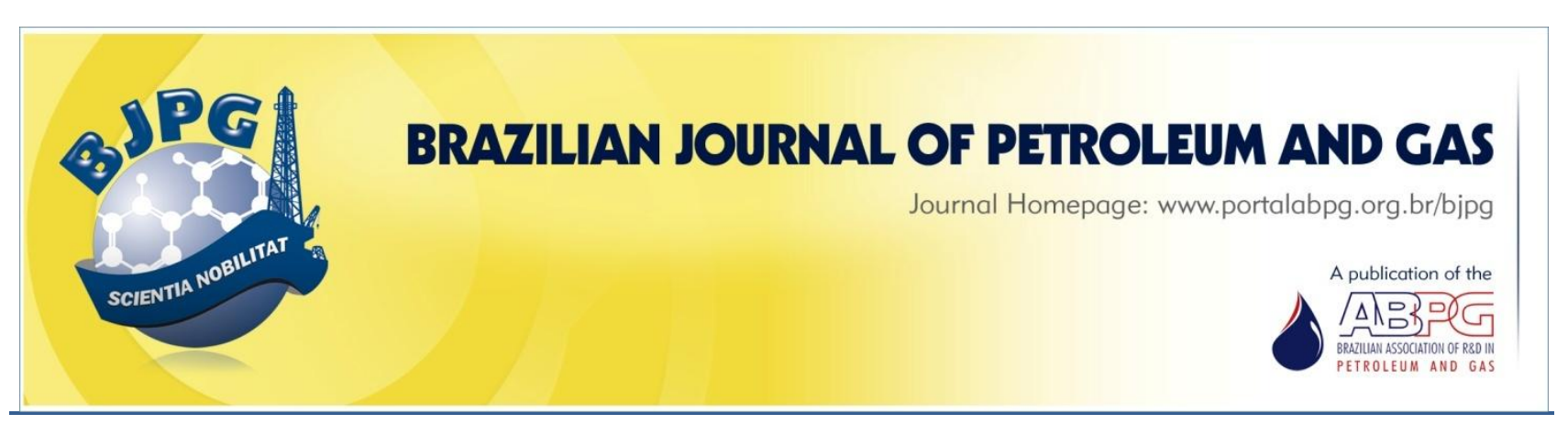

\title{
MODELING AND SIMULATION OF SECONDARY RECOVERY APPLIED TO AN OFFSHORE ULTRA-DEEP ENVIRONMENT
}

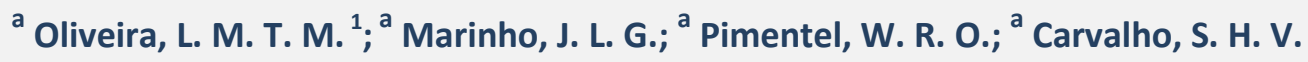 \\ ${ }^{\mathrm{a}}$ Federal University of Alagoas - UFAL, Technology Center, Maceió - AL, Brazil
}

Received: 16.10.2016 / Revised: 02.02.2016 / Accepted: 14.03.2016 / Published on line: 06.04.2016

\begin{abstract}
Secondary recovery methods have proven to be effective in recovering heavy oils from petroleum reservoirs. However, challenges concerning the offshore ultra-deep environment have prompted further research into the removal of light and intermediate oils. In this context, this study aims to conduct fluid dynamics simulation of the secondary recovery of intermediate oils from a Brazilian petroleum basin by means of water injection. The oil recovery factor and the overall recovery efficiency were evaluated. The developed model was based on a two-phase oil/water model, and the simulations were carried out with the aid of the two commercial fluid dynamic packages ICEM CFD ${ }^{\mathrm{TM}}$ and ANSYS CFX $13.0^{\mathrm{TM}}$. Water injection provided a recovery factor greater than $65 \%$ and overall efficiency of $38 \%$ recovery, showing that this method can be considered for use in the removal of intermediate oils from offshore petroleum basins. The well operation time was closely related with water saturation in the domain.
\end{abstract}

\section{KEYWORDS}

offshore; petroleum; fluid dynamic; water injection; secondary recovery

\footnotetext{
${ }^{1}$ To whom all correspondence should be addressed.

Address: Centro de Tecnologia, UFAL, Av. Lourival Melo Mota, Cidade universitária, Maceió - AL - Brazil. ZIP Code: 57000-000 | Telephone: +55 82 3214-1292 |e-mail: leonardo.m.ten@gmail.com doi:10.5419/bjpg2016-0004
} 


\section{INTRODUCTION}

The twenty-first century has seen numerous technological advances in various areas. In pharmaceutical, textile, automobile, and telecommunication fields, for instance, several innovations have helped humankind to improve the quality of life in terms of practicality and efficiency. Population growth and the desire to live longer and better have resulted in rampant consumerism. Meeting the needs of the capitalist system is crucial to maintaining social and technological standards of living, which demand the production of large amounts of energy.

Primary energy from reservoirs are considered to be the first way to exploit the oil - the difference in pressure between the reservoir and the background of the well generate the driving force required for petroleum to rise in the well (Thomas, 2004; Curbelo, 2006). Severe shortage of world petroleum reserves prompted the search for alternative strategies that would allow for better use of mature (already exploited) petroleum wells. The target was to obtain higher recovery than those afforded by the conventionally employed processes, which removed $15 \%$ of the total oil present in the petroleum reservoirs (Rosa et al., 2011).

These new approaches were designated secondary and enhanced oil recovery. These processes were based on the injection of certain fluids inside de bulk of the reservoir. They facilitated the removal of the main or residual oil from rock pores and transported oil to the surface more rapidly and efficiently. To promote oil mobility in a porous medium, secondary and enhanced oil recoveries only relied on the pressure gradient generated by the injected fluid and on changes in the physical and chemical properties of the stored oil, respectively (Santos et al., 2010; Rosa et al., 2011). Fluid injection, which is less expensive and allows for easy separation of the oil from the fluid, stands out among recovery methods. Water in its natural form (or heated) is the fluid that is the most often employed in the process.

Several works have simulated reservoirs with respect to recovery methods, oil type, and injection scheme to address process effectiveness. Cunha (2010) modeled a composite heavy oil reservoir with rectangular dimension and without symmetry. This author considered that the permeability and porosity of the rock were equal to 0.25 and $2.10^{-12}$ $\mathrm{m}^{2}$, respectively, and evaluated oil recovery after water injection using a five-spot domain scheme. In isothermal and non-isothermal conditions, this author obtained a recovery factor of $10-17 \%$ and $25 \%$, respectively. Costa et al. (2010) also simulated heavy oil recovery from the same domain via water injection under thermal and isothermal conditions, to achieve $25 \%$ and $11 \%$ recovery, respectively. Their data confirmed the results reported by Cunha (2010).

Because oil viscosity is much greater than water viscosity, one problem associated with water injection is the appearance of the viscous fingering phenomenon. The fact that water has better mobility than oil leads to an early production of oil fingers (Mariano et al., 2007).

One of the factors that can determine water injection efficiency during secondary and enhanced recovery is the heterogeneity or the geological conditions of the reservoir (Han et al., 1999). Sharma et al. (2000) stated that recovery with water makes the process economically unviable when impurities are present in the injected fluid, because the impurities reduce reservoir permeability.

Using fluid dynamics simulations, Sheng and Chen (2014) were able to produce secondary shale recovery by injecting water or gas on the basis of a Black-Oil model with four components (water, oil, dissolved gas, and solvent gas) and three phases. These authors obtained $15 \%$ and $12 \%$ recovery for gas and water injection, respectively. Other authors achieved high recoveries (between 12\% and $40 \%$ ) when they used the water injection method. For example, Faerstein (2010) observed that homogeneous reservoirs provided better recovery than heterogeneous reservoirs. In turn, Cotia (2012) found that application of the water injection method to light oils could yield a recovery factor higher than $30 \%$.

A number of methods can modify oil properties to increase oil flow in the porous medium and provide enhanced oil recovery; e.g., steam injection, polymer injection, miscible fluids injection, and application of heat (the aforementioned heated water is an advanced method), among others. Mozzafari et al. (2013) 
simulated numerically the heavy oil recovery process with continuous steam injection. These authors aimed to examine which parameters influenced oil recovery the most. On the basis of mass conservation and energy equations, they concluded that rising injection pressure and/or temperature provided recovery of up to $60 \%$. Rodrigues and Galvão (2007) simulated the effect of alternate water and steam injection on oil recovery. These authors attained recovery as high as $70 \%$ after alternating between the two fluids for eight years. Specifically, steam and water periods led to the recovery of $22 \%$ and $45 \%$, respectively.

The steam injection method affords better recovery upon use of the SAGD (Steam Assisted by Gravity Drainage) method. SAGD consists of continuously injecting steam around the reservoir (radially). The resulting convective flow tends to condense together with the oil toward a producing well located below the injector well (Kamath et al., 1993; Barillas, 2005; Fernandes et al., 2013; Wanderley et al., 2007).

Carbon dioxide injection is another recovery technique that is applied commonly worldwide. Matte (2011) assessed the feasibility of integrating an advanced recovery method with $\mathrm{CO}_{2}$ injection. This author found that $\mathrm{CO}_{2}$ partially dissolved in oil, which tended to cause swelling and decrease oil viscosity, ultimately assisting oil recovery. $\mathrm{CO}_{2}$ injection usually serves as a helper method to the natural energy of the reservoir (primary energy). To speed up production, water, instead of $\mathrm{CO}_{2}$, frequently is injected (Cotia, 2012). Injection of about $1 \mathrm{~kg}$ of $\mathrm{CO}_{2}$ into the bulk of the reservoir removes about $1 \mathrm{~kg}$ of oil at the producer well (Blunt et al., 1993).

The use of chemical methods to boost oil recovery has also grown fast, especially in the case of highly viscous oils. Leyva-Gomez and Babadagli (2013) developed fluid dynamics simulations by using a cylindrical mesh in which the domain comprised three regions-the oil field, the oil collection area, and the solvent region. By modifying the pressure and temperature ranges, these authors obtained recovery factors as high as $80 \%$ for heavy oil production when they used butane and propane as the injected fluid.

Computational fluid dynamics (CFD) is the main tool to conduct fluid flow simulation. CFD includes representative mathematical models of the process and runs simulations on the basis of a volume with geometric control (called mesh herein). The shape and physicochemical characteristics of the mesh are identical to the features of the real system flow, which is the petroleum reservoir in this case.

Therefore, this study aims to conduct a fluid dynamics standard simulation on a petroleum reservoir model containing intermediate oil with similar characteristics as the petroleum found in offshore ultra-deep basins. The commercial package ANSYS ${ }^{\text {TM }}$ CFX 13.0 aided accomplishment of the simulations. The secondary recovery process consisted in applying a quadratic domain consisting of four injection spots located at the periphery of the mesh and a central producer well. This work should contribute to predicting the feasibility of using certain methodologies to improve oil recovery from reservoirs using a simplified modeling and boundary conditions.

\section{METHODOLOGY}

The numerical simulation in the computing environment included three major steps: (1) physical model preparation and numerical grid generation, (2) mathematical model development, and (3) implementation of initial and boundary conditions and system properties.

\subsection{Definition of the physical model}

The physical model corresponded to a fraction of an offshore ultra-deep reservoir on a real scale. A symmetric portion was taken from this fraction as a volume with controlled geometry (mesh) (Figure 1). On the basis of this mesh, a numerical grid consisting of a set of finite volume that divided the area into smaller volumes was generated. In each of these volumes, partial differential equations governing the flow phenomenon were solved numerically and simultaneously on the basis of the interaction between neighboring volumes.

The proposed domain was created with the aid of the Ansys ICEM CFD ${ }^{\mathrm{TM}}$ application. The domain consisted of four peripheral injection wells and a central producer well. A conformation, known as five-spot domain, was chosen because it is the most common conformation available in the literature. The dimensions schematically indicated in Figure 2 corresponded to a rock formation in 


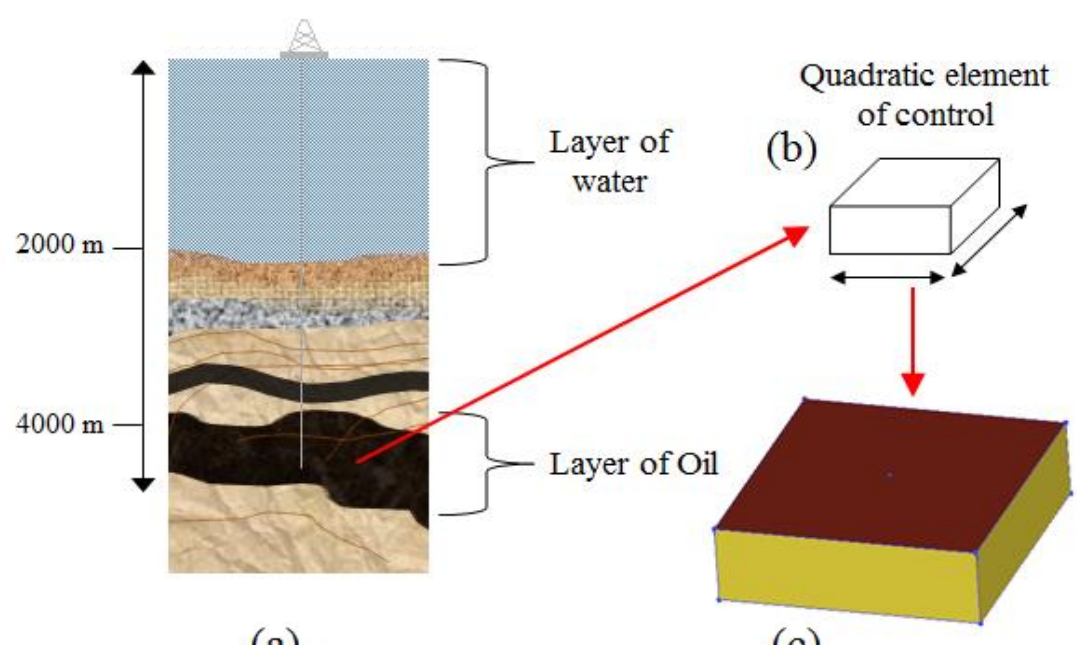

(a)

(c)

Figure 1. Overall scheme for the domain choice: (a) Geological structure of an ultra-deep basin, (b) A fraction of the reservoir (symmetrically chosen), (c) Generated geometry associated with the selected fraction.

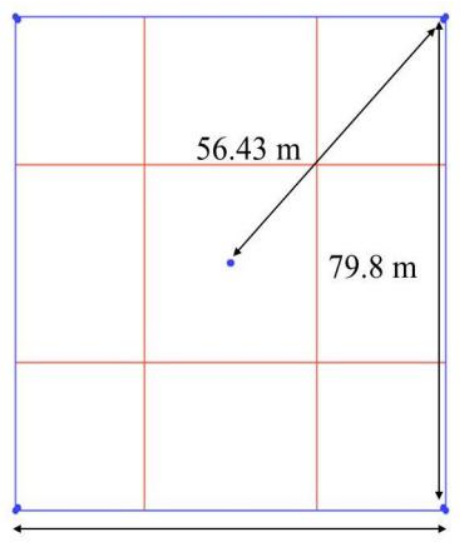

$80.4 \mathrm{~m}$

(a)

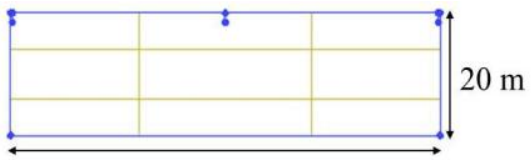

$80.4 \mathrm{~m}$

(b)

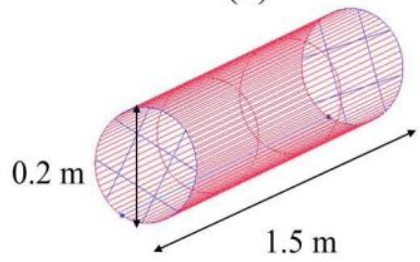

(c)

Figure 2. Reservoir geometry: (a) Top view of the reservoir, (b) Side view of reservoir, (c) Dimensions of the wells (injectors and producer).

which each side measured $80.4 \mathrm{~m}$, with a depth of $20 \mathrm{~m}$. Each peripheral well was located $56.43 \mathrm{~m}$ away from the central well; their neighboring vertices lay $78.9 \mathrm{~m}$ apart. According to Cunha (2010), the well portion considered to be inside the reservoir covered a length of $1.5 \mathrm{~m}$ and had a diameter of $0.2 \mathrm{~m}$.

On the basis of the defined geometry, an unstructured numerical grid composed of 151 thousand tetrahedral elements and 30 thousand nodes was generated, as shown in Figure 3.

\subsection{Mathematical model}

A model was developed in porous medium by employing the fundamental equations of mass, momentum, and energy conservation. This approach relied on the work by Costa et al. (2010) and made the following considerations.

- Newtonian and incompressible fluids;

- Constant properties in the reservoir;

- Simulation in transient state in 24000 hours of recovery; 


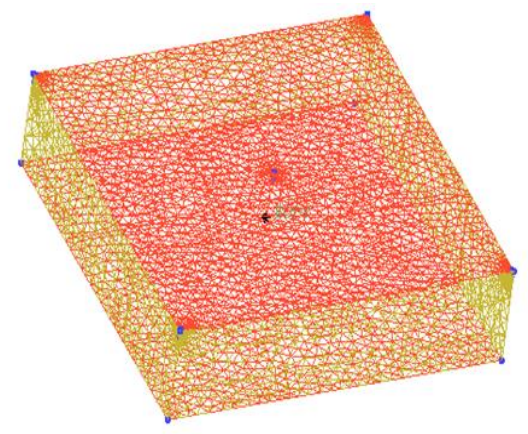

(a)

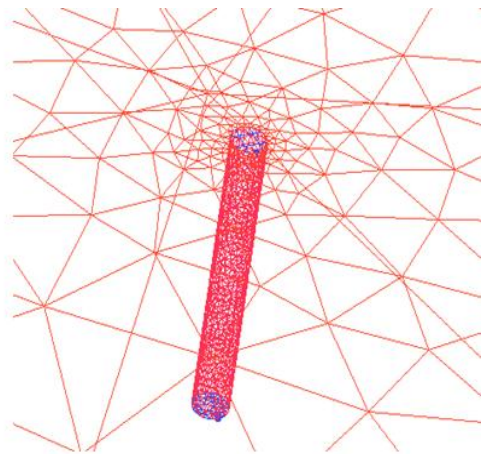

(b)

Figure 3. (a) Non-structured numerical mesh. (b) Mesh detail for one of the injection wells.

- Absence of chemical reactions;

- Fully waterproof and static reservoir walls;

- Two continuous phase flow from an EulerianEulerian Model;

- Null interfacial forces;

- Null thermal considerations.

The Ansys CFX 13.0 application selected the Darcy Model for the porous medium flow. Thus, the mass and momentum conservation equations took the following forms:

$$
\begin{aligned}
& \frac{\partial \rho \phi}{\partial t}+\nabla \cdot(\rho K \vec{U})=0 \\
& \frac{\partial \phi \rho \vec{U}}{\partial t}+\nabla \cdot(\rho(K \cdot \vec{U}) \times \vec{U}) \\
&-\nabla \cdot\left(\mu_{e} K \cdot\left(\nabla \vec{U}+(\nabla \vec{U})^{T}\right)\right) \\
&=-\phi R \cdot \vec{U}-\phi \nabla p
\end{aligned}
$$

Where $\phi$ is the porosity, $\vec{U}$ is the real 3D velocity vector, $\rho$ is the density of the fluid, $\mu_{e}$ is the effective viscosity, and $R$ is a representation of the flow resistance in the porous medium which is a direct function of the fluid and reservoir properties and of the acting external forces. $K$ is called the area porosity tensor (CFX 11.0 Guide, 2006).

Equation (1) is the definition of continuity equation; the first term represents the rate of mass accumulation, whereas the second term corresponds to the velocity gradient in porous media. Equation (2) refers to the momentum conservation equation, where the first term on the left side of the equality is the moment accumulation rate, whilst the second and third terms represent the advective flow of momentum and the diffusive flux, respectively. On the right side of the equation, one can find the terms of movement source.

According to the considerations described earlier, no mass transfer occurs during the process, which makes the third term of the left side of Equation (2) inexistent. Also, to achieve high resistance in the pores, it is necessary to apply high pressure, to equalize the imbalance generated by these resistances. Hence, the other two terms (advective and accumulation term) of the left side of Equation (2) are numerically insignificant if compared with the right side (CFX 11.0 Guide, 2006), so that the resulting equation for momentum conservation is the Darcy's Law with the following form:

$\vec{U}=\boldsymbol{R}^{-1} \cdot \nabla p$

The general equation considering the pressurevelocity coupling with Darcy's Law for each continuous phase (water and oil) is obtained by:

$$
\frac{\partial}{\partial t}\left(\rho_{\alpha} S_{\alpha} \phi\right)+\nabla \cdot\left(\rho_{\alpha} \cdot K \frac{k_{r \alpha}}{\mu_{\alpha}}(\nabla p)\right)=0
$$

Where, $\alpha$ represents the continuous phase (water or oil), $k_{r \alpha}$ is the $\alpha$ phase relative permeability, $\mu_{\alpha}$ is the $\alpha$ phase viscosity, $\rho_{\alpha}$ is the specific mass, and $S_{\alpha}$ is the $\alpha$ phase saturation.

To close the balance, it appears necessary to apply the saturation equation as:

$S_{w}+S_{o}=1$

Hence, $S_{w}$ is the water saturation and $S_{o}$ is the oil saturation. 
Table 1. Rock characteristics and the initial reservoir conditions.

\begin{tabular}{lc}
\hline \multicolumn{2}{c}{ Rock Properties } \\
\hline Permeability $\left(\mathrm{m}^{2}\right)$ & $2 \times 10^{-12}$ \\
Porosity & 0.25 \\
Initial Pressure (atm) & 580 \\
Initial Temperature (K) & 370 \\
\hline
\end{tabular}

Table 2. Petroleum characteristics and initial fluid conditions.

\begin{tabular}{lcc}
\hline Properties & Petroleum & Water \\
\hline Density $\left(\mathrm{kg} / \mathrm{m}^{3}\right)$ & 881 & 942.5 \\
Estimated molar mass $(\mathrm{kg} / \mathrm{kmol})$ & 105.47 & 18.02 \\
Viscosity (Pa.s) & 0.001 & 0.0088 \\
Initial saturation & 1 & 0 \\
Initial temperature (K) & 370 & 370 \\
\hline
\end{tabular}

Table 3. Characteristics of the simulation.

\begin{tabular}{lc}
\hline Model Compounds & Characteristics \\
\hline Interphase Transfer Model & $\begin{array}{c}\text { Mixture Model } \\
\text { Rhie Chow Option } \\
\text { Velocity Pressure Coupling }\end{array}$ \\
Pressure Interpolation Type & Trilinear \\
Velocity Interpolation Type & Trilinear \\
Advection Scheme & High Resolution \\
Convergence target & $1 \times 10^{-6}$ \\
Loops for interaction & 5 \\
\hline
\end{tabular}

\subsection{Initial and boundary conditions and fluid properties}

Due to the simplicity of the model, permeability dependencies with fluids saturation were not considered, the initial water saturation in the reservoir was null, and it presented no gaseous phase. Based on Cunha (2010) and Petrobras (2007), Table 1 lists information regarding the rock formation conditions:

Table 2 summarizes data from petroleum originated from the Santos basin, located $290 \mathrm{~km}$ off the coast of Rio de Janeiro (Petrobras, 2007), and the injected fluid (water). The molar mass was based on Cunha (2010).
To close the model, the following conditions were applied: (a) the domain was static at time zero; (b) the oil trapped in the porous medium had null velocity in the three vectorial components; and (c) the mass flow of the injected fluid was constant $-0.1 \mathrm{~kg} / \mathrm{s}$. The only surface tension considered in this model was the drag force. Therefore, the value of the drag coefficient was 0.44 (default value in Ansys CFX ${ }^{\mathrm{TM}}$ 13.0), and it remained unaltered along time.

Table 3 depicts the general characteristics of the simulation.

\subsection{Efficiency parameters}

The variation in the volumetric fraction of fluids $(f)$ has been studied; it may be defined by Equation (6):

$$
f=\frac{n_{i}}{n_{\text {total }}}
$$

Where $n_{i}$ is the volume of fluid $i$, and $n_{\text {total }}$ is the total fluid volume considered in the simulation (Rosa et al., 2011).

The recovery factor $(\% R F)$, represented by Equation (7), has also been evaluated:

$$
\% R F=\frac{V_{\text {recovered }}}{V_{\text {Initial }}} * 100
$$

Where $V_{\text {recovered }}$ is the volume of oil removed from the reservoir, and $V_{\text {Initial }}$ is the volume of oil at time zero (Rosa et al., 2011). \%RF represents the degree of oil removal and is the characteristic that is most often assessed in the field of reservoir engineering.

The Sweep Efficiency is a measure of the degree of injected fluid advance in the domain. The Horizontal Sweep Efficiency (\%SE $E_{h}$, Equation (8)) refers to the affected horizontal area; the Vertical Sweep Efficiency (\%SE $E_{v}$, Equation (9)) corresponds to the affected vertical area. There is also the Volumetric Efficiency (\%Vol.E, Equation (10)), defined as the product of the Horizontal and Vertical Sweep Efficiencies and corresponding to the total volume of the domain reached by the injected fluid (Rosa et al., 2011). 
$S E_{h}=\frac{A_{h}}{A_{T h}} * 100$

$S E_{v}=\frac{A_{v}}{A_{T v}} * 100$

Vol.E $=S E_{h} * S E_{v} * 100$

Where $A_{h}$ is the horizontal area occupied by the injected fluid, $A_{T h}$ is the total horizontal area of the domain, $A_{v}$ is the vertical area occupied by the injected fluid, and $A_{T v}$ is the total vertical area of the domain.

However, \%Vol.E does not provide the percentage of oil removal, because it is a parameter that only indicates the degree of progress of the injected fluid. Therefore, it is necessary to determine the Recovery Efficiency (\%RE), which is the product of \%Vol.E and \%RF (the displaced oil), as defined in Equation (11) (Rosa et al., 2011).

$\% R E=\%$ Vol.E* $\% R F$

To measure the operation time of the producer wells, it was necessary to use a Water/Oil Ratio (WOR), which indicates the quantity of water that comes out of the output well in relation to the oil rate at this same point.

\section{RESULTS AND DISCUSSIONS}

\subsection{Secondary recovery-Qualitative results}

The procedure described for intermediate oil recovery involved continuous injection of $0.1 \mathrm{~kg} / \mathrm{s}$ of water at $370 \mathrm{~K}$, the same temperature of the reservoir. The simulation time step was $48 \mathrm{~h}$. This segment lasted $24,000 \mathrm{~h}$, which reflected a simulation of $247 \mathrm{~min}$.

Figure 4 depicts a section of the upper region of the reservoir. This Figure reveals the formation of gradients of water concentration at eight different times (ranging from $48 \mathrm{~h}$ to $24,000 \mathrm{~h}$ ).

It is important to bear in mind that water and oil are immiscible, and that water injection into the rock increases the volume of fluid in the reservoir. Therefore, upon water injection, the rock pores undergo compression, and water exceeds its resistance. As a consequence, the injected water expels the oil present in the rock and occupies its place therein. The fact that injected fluid advances through the reservoir proves that the model is physically consistent with increased fluid volume inside the domain.

At $\mathrm{t}=48 \mathrm{~h}$, injected water starts to advance across the reservoir; a symmetric profile emerges in all four injector wells along time. At $t=4,800 \mathrm{~h}$, the water flow reaches the producer well. In other words, at this time the output no longer consists of $100 \%$ oil, but an immiscible combination of water and oil exists in the bulk, while dispersion arises in the peripheral areas. Between the times of $9,600 \mathrm{~h}$

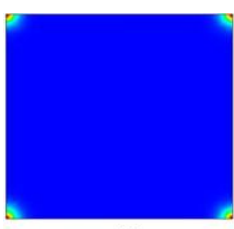

$\mathrm{t}=48 \mathrm{~h}$

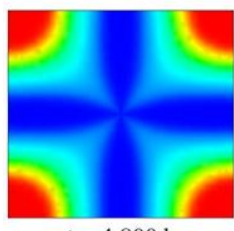

$\mathrm{t}=4,800 \mathrm{~h}$

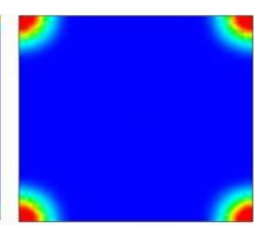

$\mathrm{t}=480 \mathrm{~h}$

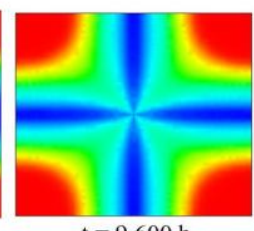

$t=9,600 h$

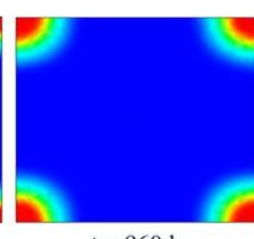

$\mathrm{t}=960 \mathrm{~h}$

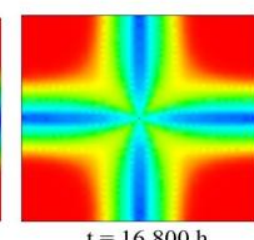

$\mathrm{t}=16,800 \mathrm{~h}$

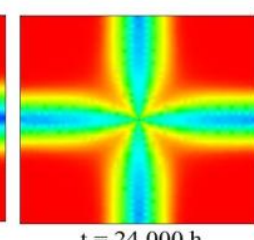

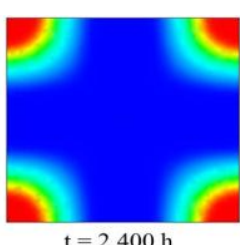

$\mathrm{t}=2,400 \mathrm{~h}$

$\mathrm{t}=24,000 \mathrm{~h}$

Figure 4. Variation in the water volumetric fraction in the upper horizontal plane of the reservoir. 


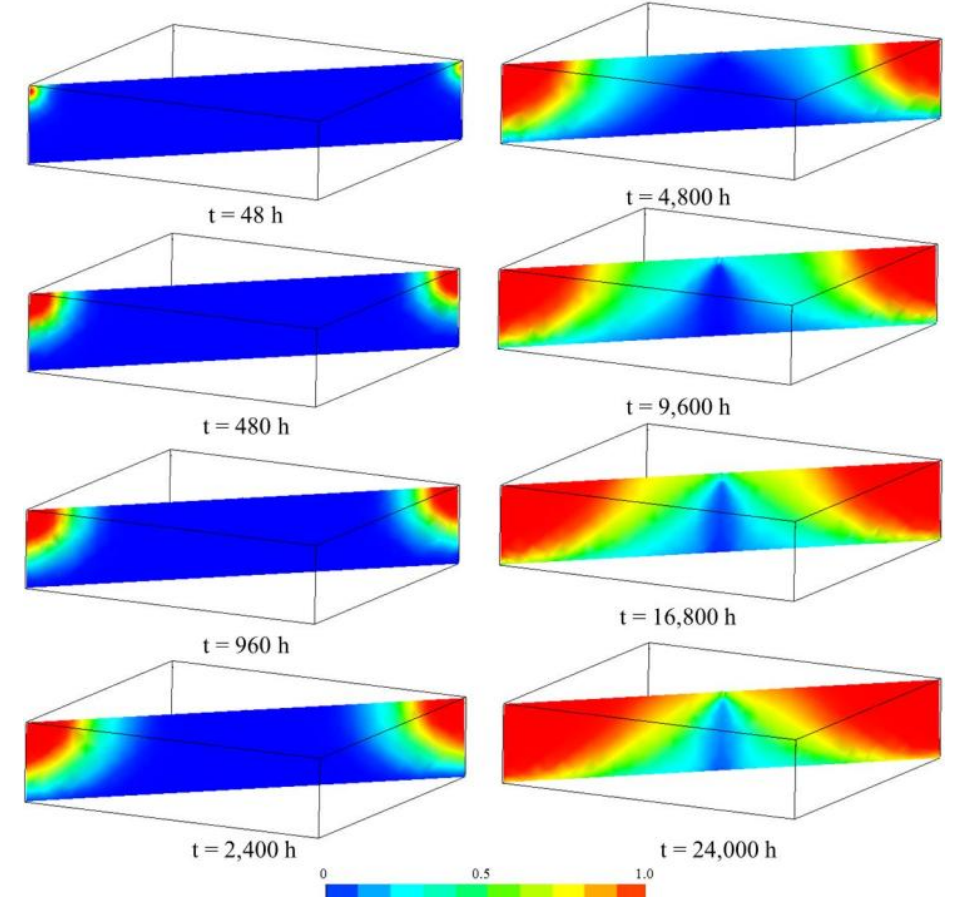

Figure 5. Variation in the water volumetric fraction in the vertical plane of the reservoir.

and $16,800 \mathrm{~h}$, the horizontal area invaded by water increases, and water better fills the pores that had been previously occupied by the injected fluid at a lower saturation ( $25 \%$ to $50 \%$ of water). Finally, at $t=24,000 \mathrm{~h}$, almost all the upper area of the reservoir is full of water at high saturation. This implies that water expels much of the oil due to the immiscibility between water and oil and to the continuous inflow of injected fluid.

The flow profile described above resembles the flow pattern reported by Rosa et al. (2011) for secondary oil recovery from a five-spot domain after water injection. Therefore, the model proposed herein provides a qualitative profile that is consistent with the theoretically expected pattern. Other authors working on reservoir simulation have also found the same flow behavior (Barbosa, 2006; Naveira, 2007; Nasri \& Dabir, 2010).

Figure 5 illustrates the vertical behavior of the volumetric fraction of the injected fluid seen from a diagonal plane in the domain.

Increasing water volumetric fraction along time gives rise to a strictly radial flow up to $t=2,400 \mathrm{~h}$. Thereafter, the profile becomes slightly elongated toward the producer well. At subsequent times, water saturation augments as oil leaves the reservoir. At the end of the recovery process, the vertical area occupied by water is much larger than the vertical area occupied by oil. Figure 6 offers a clear view of the radial flow behavior.

Authors such as Araujo and Farias Neto (2009), Cunha (2010), and Costa et al. (2010), who used the same fluid dynamic package in their recovery works, also described this type of behavior.

\subsection{Secondary recovery - Quantitative results}

\subsubsection{Recovery factor}

Figure 7 shows the response of the calculated recovery factor as a function of the process time in the presence of water stream at $0.1 \mathrm{~kg} / \mathrm{s}$.

The recovery factor (\%RF) increases along the process; the final value is $65.12 \%$. This value agrees with data reported by Faerstein (2010) and Guimarães et al. (2002), 55\% and 65\%, respectively. For a secondary oil recovery method, a value of $65 \%$ is considered high, mainly if one takes the short process time into account (Rosa et al., 2011). This result is due to a combination of ideal factors. First, injection of the fluid at constant pressure shifts the system balance toward the producer well and there isn't any variation in 


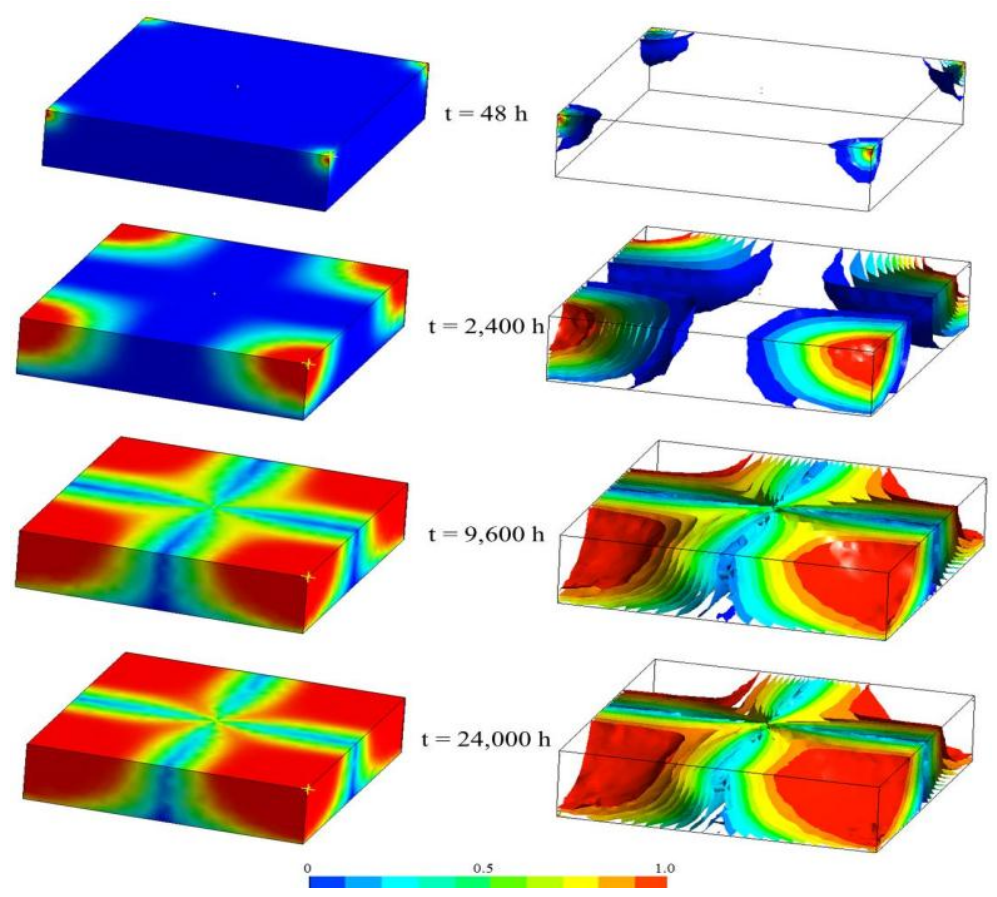

Figure 6. Radial flow behavior occurring during secondary oil recovery with water injection.

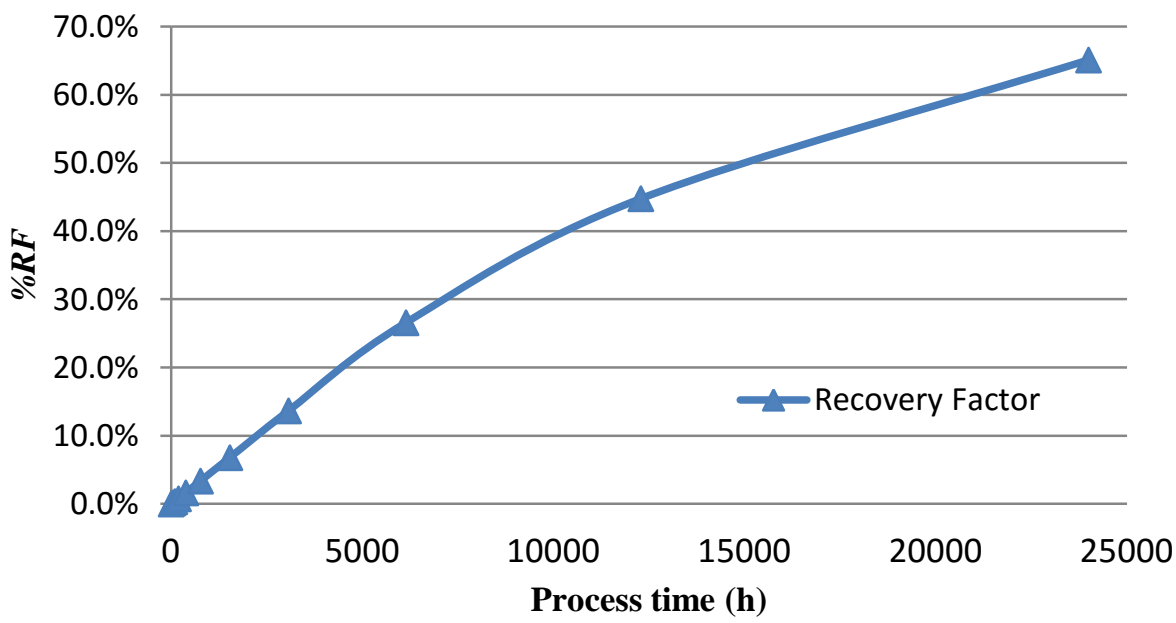

Figure 7. Radial behavior during secondary oil recovery with water injection.

properties as permeability and porosity along the domain. Second, the presence of intermediate oils in the reservoir contributes to higher \%RF. According to some authors (Sheng \& Chen, 2014; Sheorey et al., 2001; Rosa et al., 2011), heavy oil recovery usually affords $\% R F$ values ranging from $10 \%$ to $30 \%$. In the case of fluids with lower viscosity and density, like intermediate oils as compared with heavy oils, the fluid should have better mobility in the porous medium and therefore yield higher $\% R F$ values.

\subsubsection{Recovery efficiency}

Figure 8 contains the curves obtained after calculation of the sweep, volumetric, and recovery efficiencies.

The horizontal and vertical sweep efficiencies increase at a similar rate, reaching values of $78 \%$ and $75 \%$, respectively. These efficiencies result from the radial flow that develops at the outlet of the injection wells and from the lack of variation in the permeability and porosity of the rock formation 


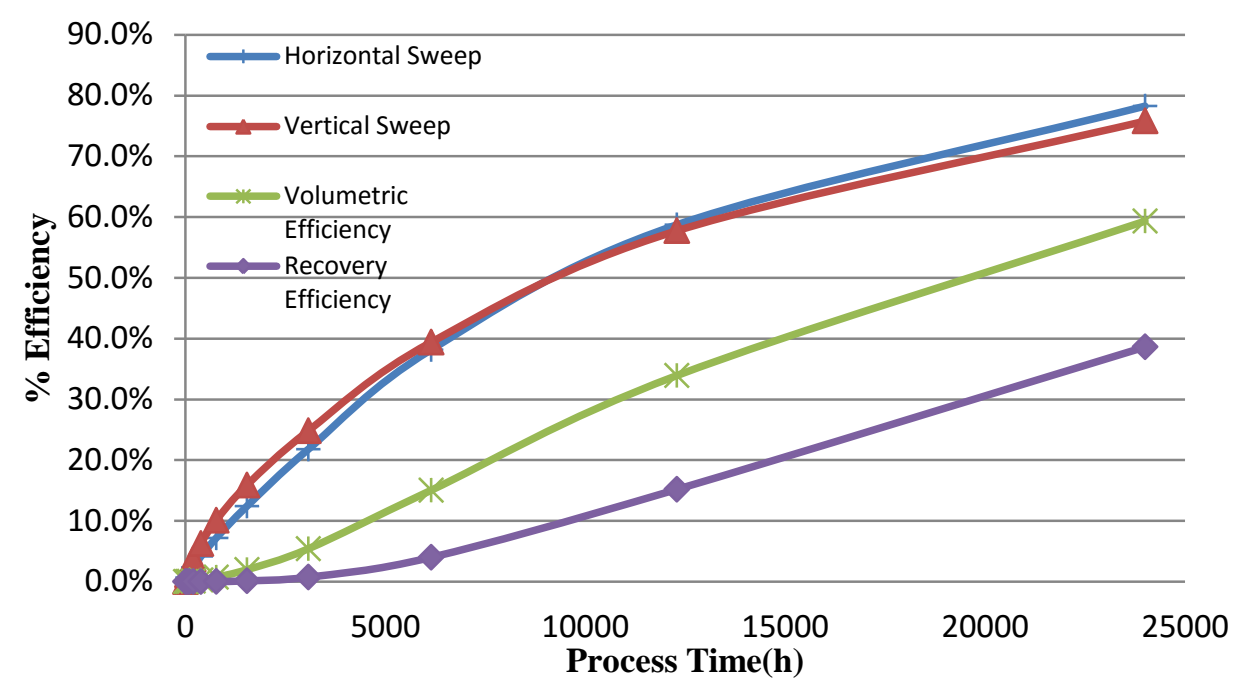

Figure 8. Efficiency behaviors for water injection at $0.1 \mathrm{~kg} / \mathrm{s}$.

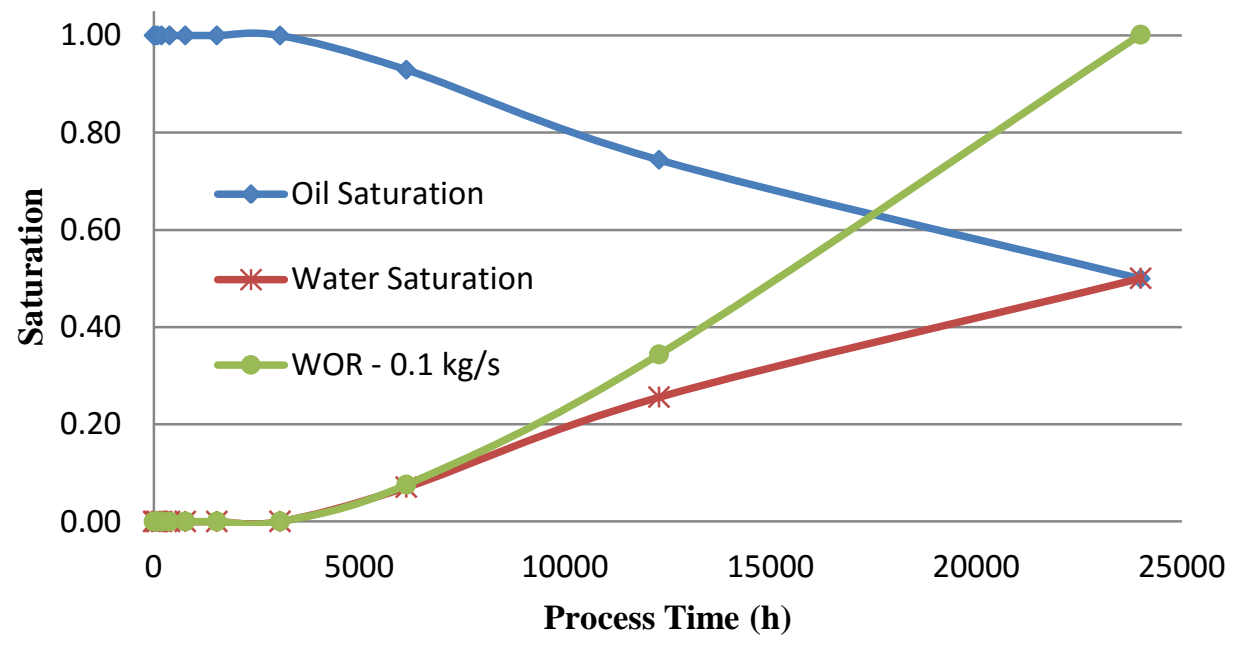

Figure 9. Saturation of water and Water/Oil ratio (WOR) of the process for water injection at $0.1 \mathrm{~kg} / \mathrm{s}$.

along the flow path. The volumetric efficiency is $59 \%$ at $\mathrm{t}=24,000 \mathrm{~h}$.

The recovery efficiency measures both the degree of water advance and the oil removal capacity of the injected fluid. \%RE values show that the process gains importance at $\mathrm{t}=10,000 \mathrm{~h}$; before that, the efficiency is lower than $10 \%$. At the end of the process, the recovery efficiency is $38.6 \%$. This result indicates that, despite the great water advance and the high recovery factor, the process does not reach a high degree of efficiency. This is a consequence of the rapid breakthrough (the time that water takes to reach the producer well), and of the high saturation of water at the output, as shown in Figure 9:
Breakthrough occurs at $\mathrm{t}=3,500 \mathrm{~h}$. Thereafter, water rapidly saturates the oil at the output through a path of water that extends until the producer well, raising the Oil/Water ratio (OWR). At $t=24,000 \mathrm{~h}$, the oil saturation is equal to the amount of water at the outlet, resulting in the production of equal amounts of both fluids.

\subsection{Influence of the injected fluid flow rate}

To understand how the injected fluid flow influences the intermediate oil recovery factor in this model, we tested five injected fluid flow rates that varied from $0.1 \mathrm{~kg} / \mathrm{s}$ to $0.5 \mathrm{~kg} / \mathrm{s}$; the other conditions remained constant, as shown in Figure 10. In accordance to the results obtained by Cunha 


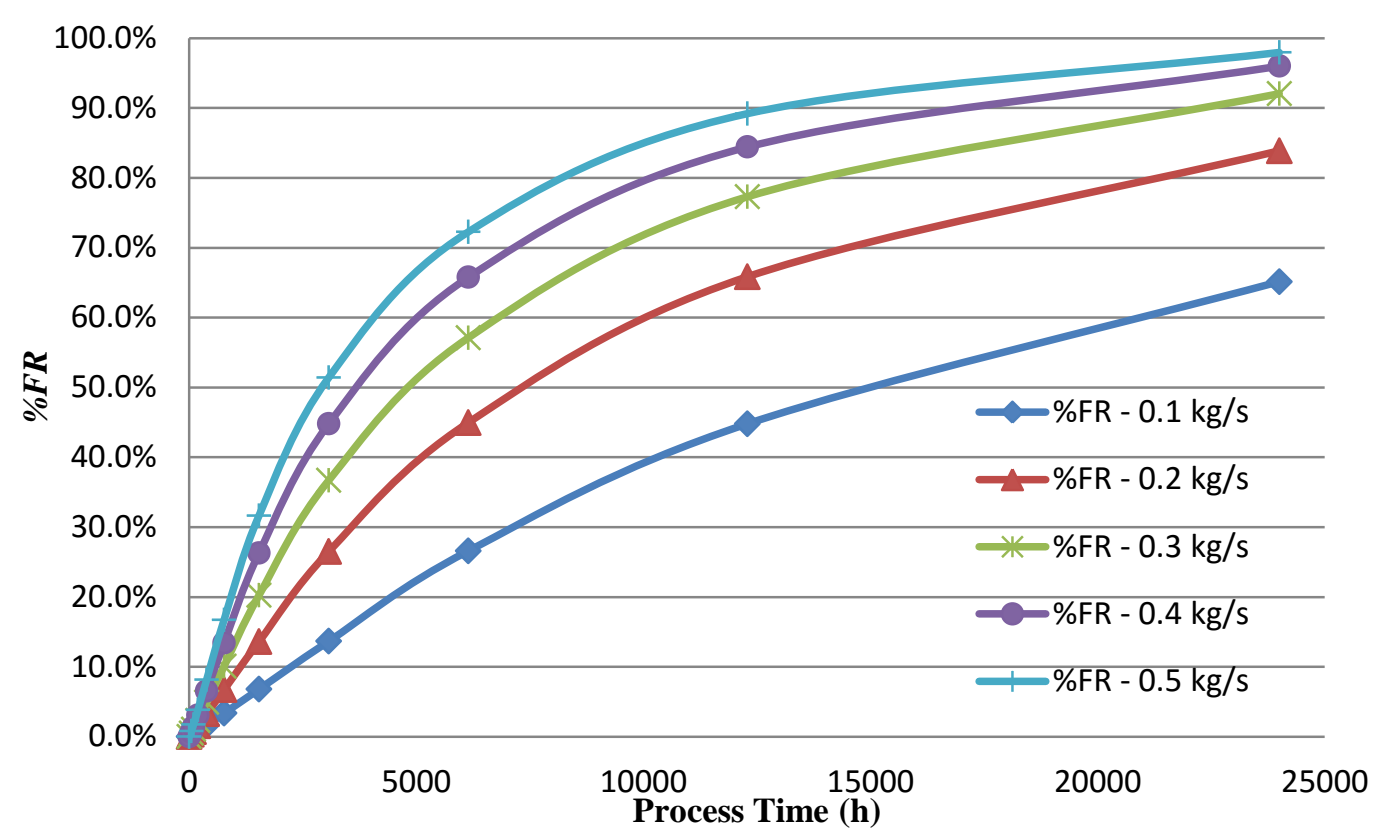

Figure 10. Influence of the injected water flow rate on \%RF.

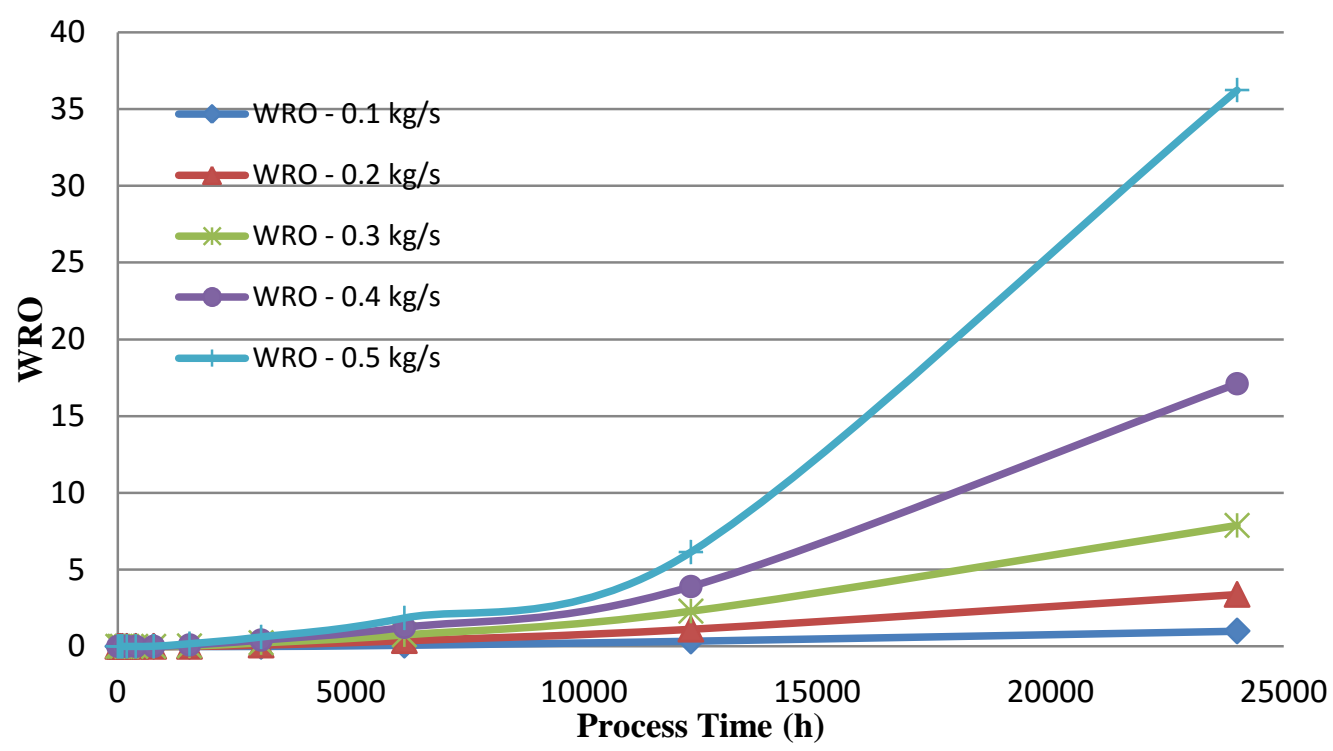

Figure 11. Influence of the injected fluid flow rate on WOR at the output.

(2010), who varied the injection flow while testing secondary heavy oil recovery, this work has also verified increased $\% R F$ for the oil, mainly because larger volumes of injected fluid fills the reservoir to a larger extent.

Figure 10 demonstrates that, at the beginning of the recovery process (from $t=0$ to $t=5,000 h$ ), $\% R F$ values rise fast. Albeit close, water flow rates of $0.1 \mathrm{~kg} / \mathrm{s}$ and $0.2 \mathrm{~kg} / \mathrm{s}$ yield widely different responses. The difference becomes more pronounced between $t=5,000 h$ and $t=15,000 h$, when $\% R F$ values differ by $20 \%$ points. Only after $15,000 \mathrm{~h}$ do these values tend to approach. As for the other tested water flow rates $(0.3 \mathrm{~kg} / \mathrm{s}, 0.4$ $\mathrm{kg} / \mathrm{s}$, and $0.5 \mathrm{~kg} / \mathrm{s}$ ), the difference in responses tends to increase up to $\mathrm{t}=5,000 \mathrm{~h}$. Thereafter, $\% R F$ values rise more slowly, and the differences between the responses obtained at the latter flow rates becomes smaller: $7 \%$ points. There is not any proximity with the real phenomenon, but it can prove that the model responses vary according to the expected. The injected fluid flow rate also 
affects the WOR at the output. According to Figure 11, WOR increases asymptotically upon rising injected fluid flow rate.

Despite the ascending rate, the plot in Figure 11 indicates that the difference in WOR as a function of the flow rate is very small until $t=3,500 \mathrm{~h}$. More marked differences arise after $t=10,000 \mathrm{~h}$, when WOR starts to grow at a higher rate, especially for injected fluid flow rates of $0.4 \mathrm{~kg} / \mathrm{s}$ and $0.5 \mathrm{~kg} / \mathrm{s}$. Indeed, WOR growth assumes an exponential behavior from WOR equal to 17 and 31 for injected fluid flow rates of $0.4 \mathrm{~kg} / \mathrm{s}$ and $0.5 \mathrm{~kg} / \mathrm{s}$, respectively. This result indicates that 17 and 31 parts of water and 1 part of oil exist at the output well for the experiment conducted at an injected fluid flow rate of $0.4 \mathrm{~kg} / \mathrm{s}$ and $0.5 \mathrm{~kg} / \mathrm{s}$, respectively. Therefore, higher injected fluid flow rates are not productive, because they afford high WRO at $24,000 \mathrm{~h}$.

\subsection{Producer well lifetime}

The lifetime of a producing well will vary as a function of the pressure in the natural reservoir and of the pressure imposed by the adopted recovery method. If one considers a constant differential pressure, the lifetime becomes a function of the injected fluid saturation at the output well.

This work considered that the operation time of a well for each given flow corresponds to the time point when the water volumetric fraction in the producer well is $50 \%$. Above this value, there is greater removal of water as compared with oil. One can say that the process becomes technically unfeasible, although only an economic analysis can accurately afford the feasibility.

Table 4. Average viable period of the recovery process.

\begin{tabular}{cc}
\hline $\begin{array}{c}\text { Injected fluid } \\
\text { flow rate } \\
\mathbf{( k g / s )}\end{array}$ & $\begin{array}{c}\mathbf{5 0 \%} \text { of water } \\
\text { saturation at the } \\
\text { output well }(\mathbf{h})\end{array}$ \\
\hline 0.1 & 24,000 \\
0.2 & 11,616 \\
0.3 & 7,755 \\
0.4 & 5,520 \\
0.5 & 4,445 \\
\hline
\end{tabular}

Table 4 shows the estimated producer well lifetime for each one of the injected fluid flow rate.

\section{CONCLUSIONS}

The model employed herein used mass and momentum conservation equations as well as the properties aimed at ultra-deep intermediate oil (low permeability, high porosity, and API degree of 29) to simulate a five-spot domain scheme consisting of four input wells and one output well at a constant injected fluid flow rate of $0.1 \mathrm{~kg} / \mathrm{s}$. The simulation recovery process lasted 24,000 hours and yielded a recovery factor of $65 \%$ and total efficiency of $38.6 \%$, with large sweep area. This points out that the water injection process is viable as a secondary oil recovery method for this kind of basin in the simplified model applied.

Increasing injected water flow rate augmented the recovery factor. However, water saturation also increased at the producer well, culminating in low oil recovery. Therefore, a lower injected water flow rate should be the preferred path for successful oil recovery in this case.

\section{NOMENCLATURE}

Greek letters:

$\phi$ - Porosity [-]

$\rho$ - Density $\left[\mathrm{kg} / \mathrm{m}^{3}\right]$

$\rho_{\alpha^{-}}$-Specific mass from $\alpha$ phase $\left[\mathrm{kg} / \mathrm{m}^{3}\right]$

$\mu_{e}$ - Effective viscosity [Pa.s]

$\mu_{\alpha}$-Absolute viscosity from $\alpha$ phase [Pa.s]

Symbols:

$A_{h}$ - Horizontal area filled by injector fluid $\left[\mathrm{m}^{2}\right]$

$A_{v}$ - Vertical area filled by injector fluid $\left[\mathrm{m}^{2}\right]$

$A_{T h}$ - Total horizontal area of the domain $\left[\mathrm{m}^{2}\right]$

$A_{T v}$ - Total vertical area of the domain $\left[\mathrm{m}^{2}\right]$

$f$ - Volume fraction [-]

$K$ - Tensor area porosity $\left[\mathrm{m}^{2}\right]$

$k_{r \alpha}$ - Relative permeability [-] 
$n_{i}$ - Volume of fluid $i\left[\mathrm{~m}^{3}\right]$

$n_{\text {total }}$ - Total fluid volume of the domain $\left[\mathrm{m}^{3}\right]$

$p$ - Pressure $[\mathrm{Pa}]$

$R$ - Porous resistance [-]

$R E$ - Recovery efficiency [-]

$R F$ - Recovery factor [-]

$S_{\alpha}-\alpha$ phase saturation [-]

$S E_{h}$ - Horizontal swept efficiency [-]

$S E_{v}$ - Vertical swept efficiency [-]

$t$ - Time [s]

$\vec{U}$ - Vector real velocity $[\mathrm{m} / \mathrm{s}]$

$V_{\text {Initial }}$ - Initial volume founded at domain $\left[\mathrm{m}^{3}\right]$

$V_{\text {recovered }}$ - Volume of recovered fluid $\left[\mathrm{m}^{3}\right]$

Vol.E - Volumetric efficiency [-]

\section{ACKNOWLEDGEMENTS}

The authors acknowledge the financial support of the National Agency of Petroleum, Gas and Biofuels (ANP) through ANP's Human Resources Program (PRH-40) and the Laboratório de Sistemas de Separação e Otimização de Processos - LASSOP - for the infrastructure used.

\section{REFERENCES}

Araujo, M. de V.; Farias Neto, S. R. Análise Numérica do Comportamento do Óleo em Reservatórios de Petróleo Quando se Injeta Água. In: VIII Congresso Brasileiro de Engenharia Química em Iniciação Científica, 2009, Proceeding VIII Cobeq-IC, Uberlândia - MG, 1 CD-ROM. (in Portuguese).

Barbosa, E. S. Escoamento bifásico em reservatórios petrolíferos heterogêneos. $115 f$. Dissertação de Mestrado. Programa de PósGraduação em Engenharia Química. Universidade Federal de Campina Grande, 2006. (in Portuguese).
Barillas, J. L. M. Estudo do Processo de Drenagem Gravitacional de Óleo com Injeção Contínua de Vapor em Poços Horizontais. 163f. Dissertação de Mestrado. Programa de PósGraduação em Engenharia Química. Universidade Federal do Rio Grande do Norte, 2005. (in Portuguese).

Blunt, M.; Fayers, F. J.; Orr Jr, F. M. Carbon dioxide in enhanced oil recovery. Energy Conversion and Management, v. 34, p. 1197-1204, 1993.

http://dx.doi.org/10.1016/0196-8904(93)90069-M

CFX GUIDE 11.0, Ansys, Harwell, UK, 2006.

Costa, A. B.; Araujo, M. V.; Farias Neto, S. R.; Lima, A. G. B. Simulação Numérica de Escoamento Não Isotérmico de Óleos Pesados Induzido pela Injeção de Fluidos em Reservatório de Petróleo. In: VII Congresso de Iniciação Científica da Universidade Federal de Campina Grande, 2010, Proceeding ISSN 2177-113X, Campina Grande - PB, $1 \mathrm{CD}-\mathrm{ROM}$ (in Portuguese).

Cotia, D. M. R. Análise da Recuperação Avançada de Óleo Através da Injeção de $\mathrm{CO}_{2}$ Alternado com Água Sob Incerteza Geológica. 158f. Monografia de Graduação. Universidade Federal do Rio de Janeiro, Curso de Engenharia de Petróleo, 2012. (in Portuguese).

Cunha, A. L. Recuperação Avançada NãoIsotérmica de óleos Pesados em Reservatórios de Petróleo via Simulação Numérica. 88f. Dissertação de Mestrado. Programa de Pós-Graduação em Engenharia Química, Universidade Federal de Campina Grande, 2010. (in Portuguese).

Curbelo, F. D. S. Recuperação Avançada de Petróleo Utilizando Tensoativos. 170p. Tese de Doutorado. Programa de Pós-Graduação em Engenharia Química, Universidade Federal do Rio Grande do Norte, 2006. (in Portuguese).

Faerstein, M. Impactos da molhabilidade da rocha na produção e recuperação de petróleo. 165f. Dissertação de Mestrado. Programa de PósGraduação em Engenharia Civil, Universidade Federal do Rio de Janeiro, 2010. (in Portuguese). 
Fernandes, G. M. D.; Barillas, J. L. M.; Dutra Jr, T. V. Estudo da influência da capacidade máxima de produção do poço em modelos com perda de carga e calor no poço injetor no processo de drenagem gravitacional assistida por vapor (SAGD). In: Congresso Brasileiro de P\&D em Petróleo e Gás, 2013, Proceeding 7 PDPETRO 2013 Aracajú - SE, 1 CD-ROM (in Portuguese).

Guimarães, L. N.; Costa, L. M.; Santos, E. A.; Costa, A. P.; Pontes Filho, I. D. S. Multiphase flow of water and oil in heterogeneous reservoir. Mecánica Computacional, v.21, p. 670-682, 2002.

Han, D.; Yang, C.; Zhang, Z.; Lou, Z.; Chang, Y. Recent development of enhanced oil recovery in China. Journal of Petroleum Science and Engineering, v. 22, p. 181-188, 1999. http://dx.doi.org/10.1016/50920-4105(98)00067-9

Kamath, V. A.; Sinha, S.; Hatzignatiu, U. Simulation study of steam-assisted gravity drainage process in Ungu Tar Sand reservoir. In: Western Regional Meeting Held in Anchorage, 1993, Proceeding W.R.M. 1993, Anchorage - AK. http://dx.doi.org/10.2118/26075-MS

Leyva-Gomez, H.; Babadagli, T. Numerical simulation of heavy-oil/bitumen recovery by solvent injection at elevated temperatures. Journal of Petroleum Science and Engineering, v.110, p. 199-209, 2013.

http://dx.doi.org/10.1016/i.petrol.2013.08.015

Mariano, G. C.; Cardoso, F. F.; Lopes, T. J.; Quadri, M. G. N; Machado, R. A. F.; Quadri, M. B. Um estudo experimental sobre a instabilidade da interface no deslocamento de óleo por injeção de água. In: Congresso Brasileiro de P\&D em Petróleo e Gás, 2007, Proceeding $4^{\circ}$ PDPETRO 2007, Campinas - SP, 1 CD-ROM (in Portuguese).

Matte, A. C. Métodos especiais de recuperação avançada de petróleo utilizando injeção de dióxido de carbono gasoso e seus processos derivados. 63f. Monografia de Graduação. Universidade Federal do Rio de Janeiro, Curso de Engenharia de Petróleo, Rio de Janeiro, 2011. (in Portuguese).

Mozzafari, S.; Nikookar, M.; Ehsani, M. R.; Sahranavard, L.; Roayaie, E.; Mohammadi, A. H. Numerical modeling of steam injection in heavy oil reservoirs. Fuel, v.112, p.185-192, 2013.

http://dx.doi.org/10.1016/j.fuel.2013.04.084
Nasri, Z.; Dabir, B. Modeling of carbonate oil reservoirs in imbibition displacement with considering asphaltene deposition. Journal of Petroleum Science and Engineering, v.70, p. 273281, 2010.

http://dx.doi.org/10.1016/i.petrol.2009.11.020

Naveira, L. P. Simulação de reservatórios de petróleo utilizando o método de elementos finitos para recuperação de campos maduros e marginais. 97p. Dissertação de Mestrado. Programa de Pós-Graduação de Engenharia, Universidade Federal do Rio de Janeiro. Rio de Janeiro, 2007. (in Portuguese).

PETROBRAS. Petróleo Brasileiro S. A. Pre-salt reservoirs offshore Brazil: Perspectives and Challenges. In: Energy Conference, 2007, Proceeding E.C. 2007, Miami - FL.

Rodrigues, M. A. F.; Galvão, E. R. V. P. Estudo da Injeção de Água Junto ao Vapor como Método de Recuperação Avançada em Campos de Óleo Pesado. In: Congresso Brasileiro de P\&D em Petróleo e Gás, 2007, Proceeding $4^{\circ}$ PDPETRO 2007, Campinas - SP, 1 CD-ROM (in Portuguese).

Rosa, A. J.; CARVALHO, R. S.; XAVIER, J. A. D. Engenharia de Reservatórios de Petróleo. Rio de Janeiro: Editora Interciência, 2011, 810p. (in Portuguese).

Santos, P. E. S.; Araujo, R. B.; Lima, A. M. de C.; Santana, A. P. S. C. Métodos de Recuperação Secundária Convencionais. Cadernos de Graduação. Ciências Exatas e Tecnológicas, v 12, p. 1-13, 2010. (in Portuguese).

Sharma, M. M.; Pang, S.; Wennberg, K. E.; Morgenthaler, L. N. Injectivity Decline in WaterInjection Wells: An Offshore Gulf of Mexico Case Study. SPE Prod. \& Facilities, v. 15, p.6-13, 2000. http://dx.doi.org/10.2118/60901-PA

Sheorey, T.; Muralidhar, K.; Mukherjee, P. P. Numerical experiments in the simulation of enhanced oil recovery from a porous formation. Int. J. Therm. Sci., v. 40, p. 981-997, 2001. http://dx.doi.org/10.1016/S1290-0729(01)01284-4

Sheng, J. J.; Chen, K. Evaluation of the EOR potential of gas and water injection in shale oil reservoirs. Journal of Unconventional Oil and Gas Resources, v. 5, p. 1-9, 2014. http://dx.doi.org/10.1016/i.juogr.2013.12.001 
Thomas, J. E. Fundamentos da Engenharia de Petróleo. Rio de Janeiro: Editora Interciência: Petrobrás, 2a Ed., 2004. 274p.

Wanderley, J. B. de M.; Barillas, J. L. M.; Guedes Junior, G. A.; Nascimento, D. M. Estudo de parâmetros operacionais do processo para aplicação do processo de drenagem gravitacional assistido com vapor em reservatórios heterogêneos do nordeste brasileiro. In: Congresso Brasileiro de P\&D em Petróleo e Gás, 2007, Proceeding $4^{\circ}$ PDPETRO 2007, Campinas - SP, 1 CDROM (in Portuguese). 